\title{
ELIMINAÇÃO DE CLOGGING E AUMENTO DA PERFORMANCE DE LINGOTABILIDADE DOS AÇOS ALTO ALUMÍNIO PRODUZIDOS NO RH*
}

\author{
Willian Facundes ${ }^{1}$ \\ Marlon José dos Anjos Silva ${ }^{2}$ \\ Túlio Carvalho da Silva Araújo ${ }^{3}$
}

\section{Resumo}

Foram estudados os aspectos termoquímicos e operacionais dos aços ultrabaixo carbono com alto teor de silício e alumínio, visando eliminar a obstrução da válvula gaveta (clogging) que gera transtornos operacionais como: redução da velocidade de lingotamento, retorno de aço remanescente na panela para o convertedor e interrupções de sequenciais. Realizou-se também a caracterização do material solidificado no interior da válvula gaveta utilizando técnicas de microscopia óptica e eletrônica. Os estudos mostraram que as inclusões eram formadas principalmente por alumínio, contendo também oxigênio e cálcio. Visando reduzir a quantidade de alumina no aço, substituiu-se o alumínio pelo ferro silício como agente desoxidante e exotérmico. Após essa alteração conseguiu-se eliminar a obstrução de válvula gaveta e consequentemente, os transtornos operacionais.

Palavras-chave: Ultrabaixo carbono; Lingotamento; Válvula gaveta; Alumina.

\section{CLOGGING REMOVAL AND INCREASE OF CASTABILITY PERFORMANCE OF HIGH ALUMINUM STEEL PRODUCED IN RH}

\begin{abstract}
Thermochemical and operational aspects of ultra low carbon steel with high content of aluminum and silicon were studied in order to eliminate the clogging occurrence. The clogging generates operational problems such as the decrease of casting speed, the return of remaining steel from the ladle to the converter and sequential interruptions. It was also made a characterization of solidified material inside the slide gate nozzle valve using optical and electronic microscopy techniques. The studies showed that inclusions were mainly formed by aluminum, but also by oxygen and calcium. Aiming to reduce the amount of alumina, metallic aluminum was replaced by ferrosilicon as a deoxidizing and exothermic agent. As a result, it was possible to eliminate slide gate nozzle obstruction hence sequential interruptions and others associated problems.
\end{abstract}

Keywords: Ultra low carbon; Casting; Slide gate nozzle; Alumina.

Engenheiro de Materiais, Engenheiro Produção Pleno, Usiminas Ipatinga, Ipatinga, MG, Brasil. Membro da ABM, Engenheiro Metalurgista, Msc, Especialista de Produção Pleno, Usiminas Ipatinga, Ipatinga, MG, Brasil.

3 Membro da ABM, Engenheiro de Materiais, Gerente de Convertedores, Usiminas Ipatinga, Ipatinga, MG, Brasil. 


\section{INTRODUÇÃO}

As inclusões são constituintes indesejáveis ao aço. Elas podem ser divididas em óxidos, sulfetos, nitretos e aluminatos [1]. Nos aços acalmados ao alumínio os principais problemas enfrentados na Usiminas estão relacionados, principalmente às inclusões contendo óxidos de alumínio, formados durante o refino e o lingotamento dos aços. As inclusões possuem densidades inferiores a do aço e tendem a flutuar e serem absorvidas pela escória. As inclusões de alumina têm uma velocidade de ascensão menor que as de sílica, este fato pode ser atribuído à diferença de densidade entre elas, aproximadamente $3,14 \mathrm{~g} / \mathrm{cm}^{3}$ para alumina e $1,95 \mathrm{~g} / \mathrm{cm}^{3}$ para a sílica. Outro mecanismo é devido as inclusões de sílica precipitarem sobre as inclusões de $\mathrm{MnO}$ formando uma nova fase que cresce e flutua rapidamente [2]. Porém, caso não se disponha de tempo suficiente para essa flutuação, algumas inclusões podem permanecer no banho. Elas podem ser arrastadas pelo fluxo de aço e aderirem à válvula gaveta ou serem transportadas até o molde ficando aprisionadas no aço solidificado, podendo causar defeitos superficiais e internos [3]. O sistema de válvula gaveta da panela de aço é um conjunto complexo, composto por: tijolo sede, válvula superior, placa superior, placa inferior e válvula inferior. $\mathrm{Na}$ figura 1 é apresentado este conjunto.

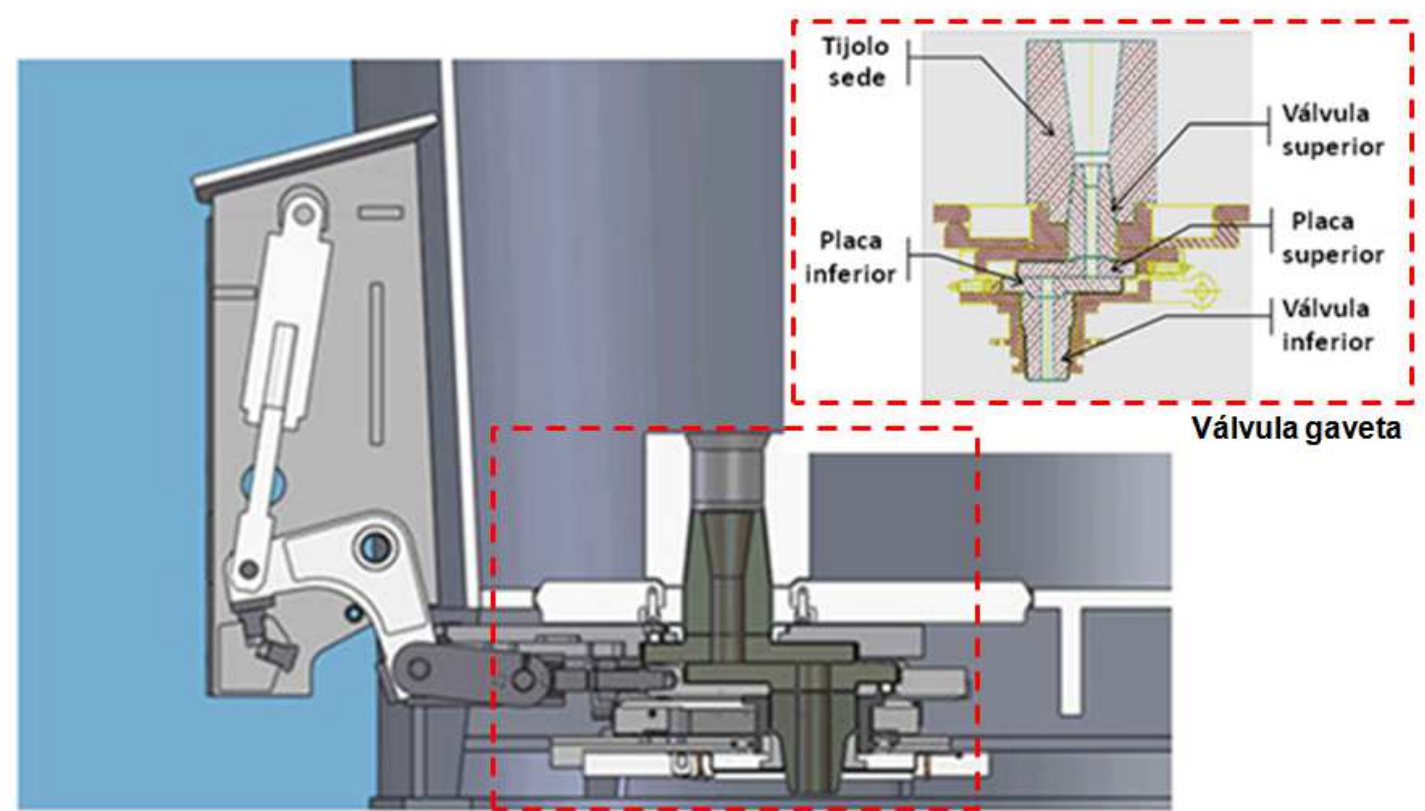

Figura 1 - Sistema de válvula gaveta no fundo da panela de aço. [Fonte: Interna Usiminas].

No início de lingotamento a placa e a válvula inferiores se deslocam permitindo a passagem de aço e promovendo o enchimento do distribuidor. Após esse deslocamento a velocidade de saída do aço tende a ser elevada, uma vez que ela é função da pressão ferrostática relacionada à maior altura de aço na panela. No transcorrer do lingotamento a altura de aço diminui, assim como sua velocidade de saída. Para compensar essa diminuição aumenta-se a abertura da válvula para manter a vazão de aço e o nível no distribuidor constante. A placa inferior semiaberta se torna um modificador de linhas de fluxo aumentando bruscamente a turbulência nessa região [3]. Essa turbulência eleva consideravelmente a probabilidade de colisões entre as inclusões de alumina podendo formar aglomerados chamados clusters, conforme visto na figura 2 [4]. 

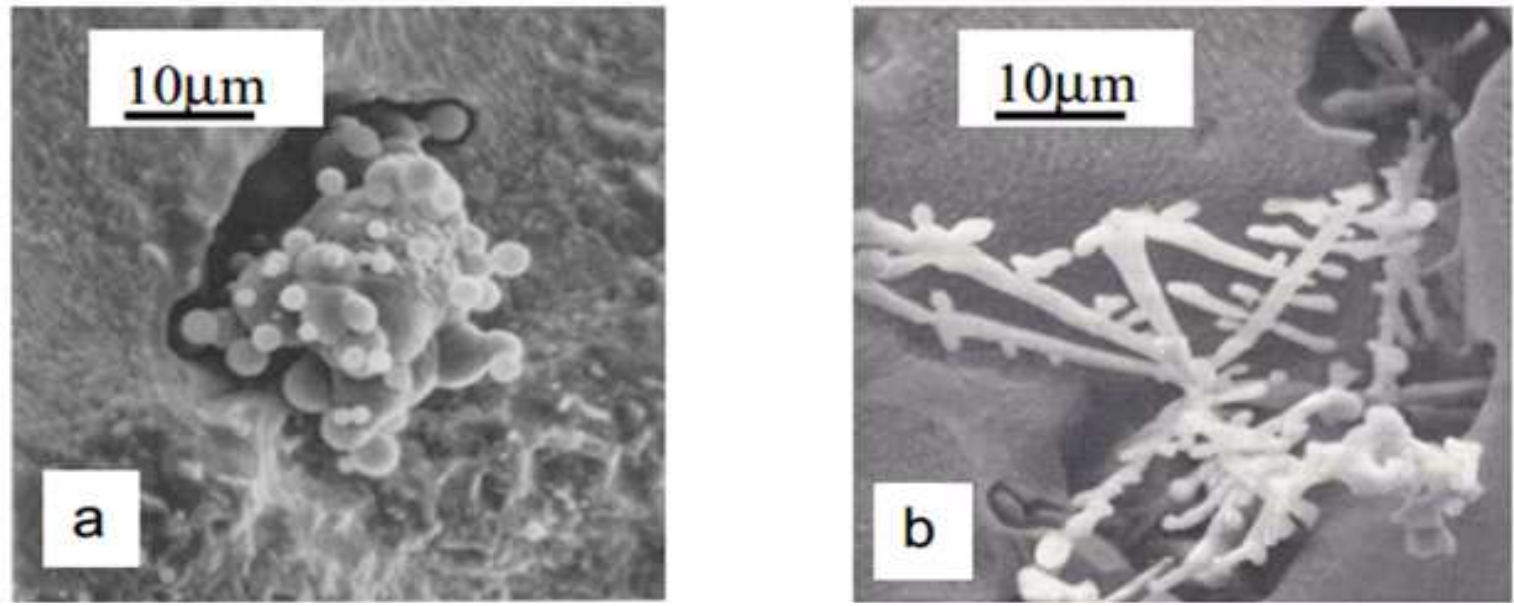

Figura 2 - Morfologias de algumas inclusões de alumina: a) cluster de alumina b) cluster de alumina dendrítico [4].

Essa placa semiaberta é também uma região propícia ao acúmulo das inclusões. Faco [5] concluiu que, a ocorrência de obstrução de válvula gaveta está associada a depósitos de inclusões sólidas, sendo frequentes os depósitos de óxidos de alumínio (alumina). Esse acúmulo de inclusões pode levar a obstrução parcial ou total dessa válvula comprometendo o fluxo de aço, podendo ocorrer redução de velocidade de lingotamento, retorno de aço remanescente na panela para o convertedor, interrupções de série, perda de produtividade e qualidade, entre outros. Um esquema do fenômeno de obstrução da válvula gaveta da panela é mostrado na figura 3.
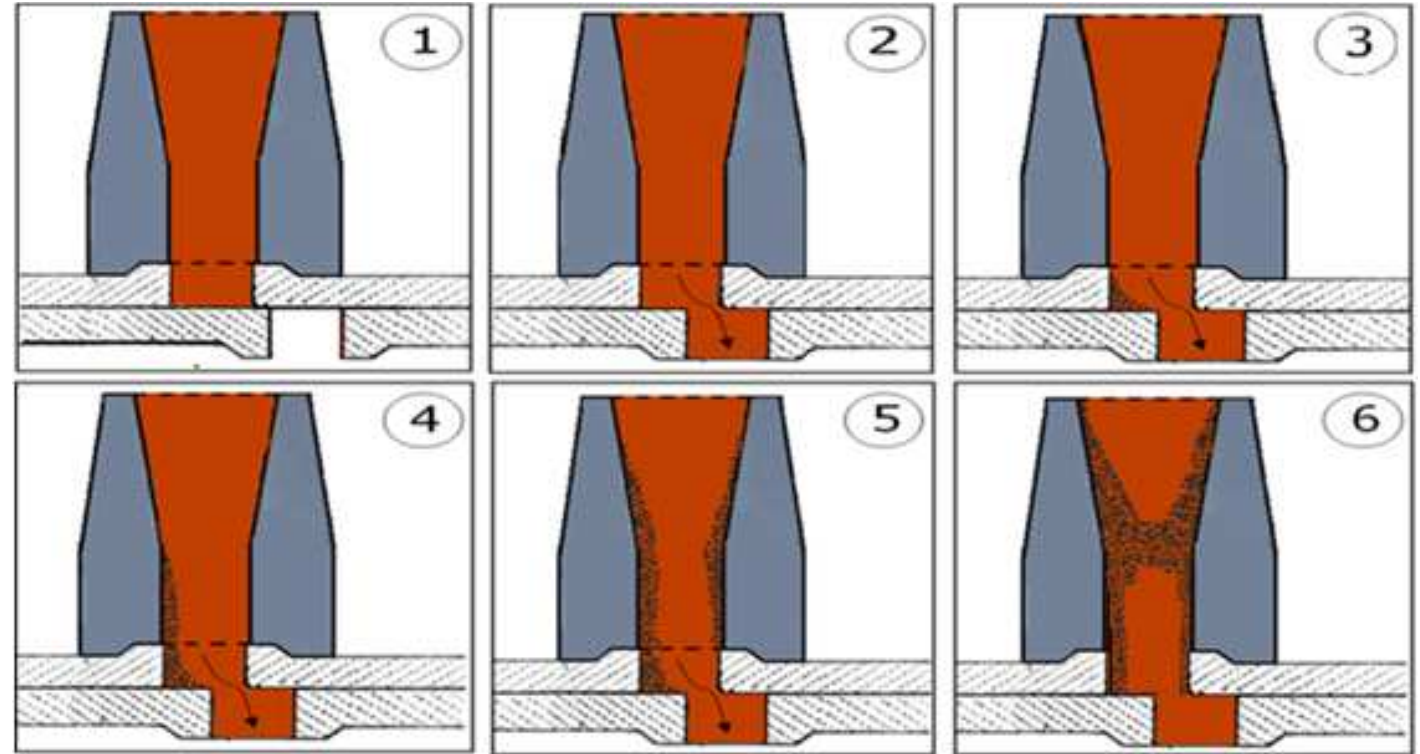

Figura 3 - Esquema do fenômeno de obstrução da válvula gaveta da panela. [Fonte: Interna Usiminas].

(1) Válvula fechada aguardando partida;

(2) Válvula semiaberta e condições normais de lingotamento;

(3) Início de formação de clogging na placa superior;

(4) Formação de clogging na placa superior e válvula superior;

(5) Estágio avançado de formação de clogging;

(6) Obstrução completa da válvula superior impedindo o fluxo de aço. 
O processo de fabricação do aço ultrabaixo carbono no desgaseificador a vácuo $\mathrm{RH}$ necessita de alto teor de oxigênio no aço para promover a descarburação. Posteriormente, deve-se adicionar elementos com afinidade pelo oxigênio para promover a desoxidação. Na Usiminas o desoxidante mais utilizado é o alumínio. Sabe-se que quanto maior o teor de oxigênio solúvel maior será a geração de alumina no aço.

Os aços da qualidade Usicore possuem teor de alumínio entre 0,35 a $0,55 \%$ e silício entre 0,70 a $0,90 \%$. Devido a esses altos teores, esses elementos apresentam maior tendência à oxidação gerando ainda mais alumina e aumentando o número de inclusões presentes no aço, aumentando a probabilidade de formação de clogging de alumina. Por este motivo a maior contribuição nas ocorrências de retorno de aço, para aços qualidade Usicore, é devido à obstrução de válvula gaveta, sendo esse responsável por $67 \%$ dos casos conforme apresentado na figura 4 .

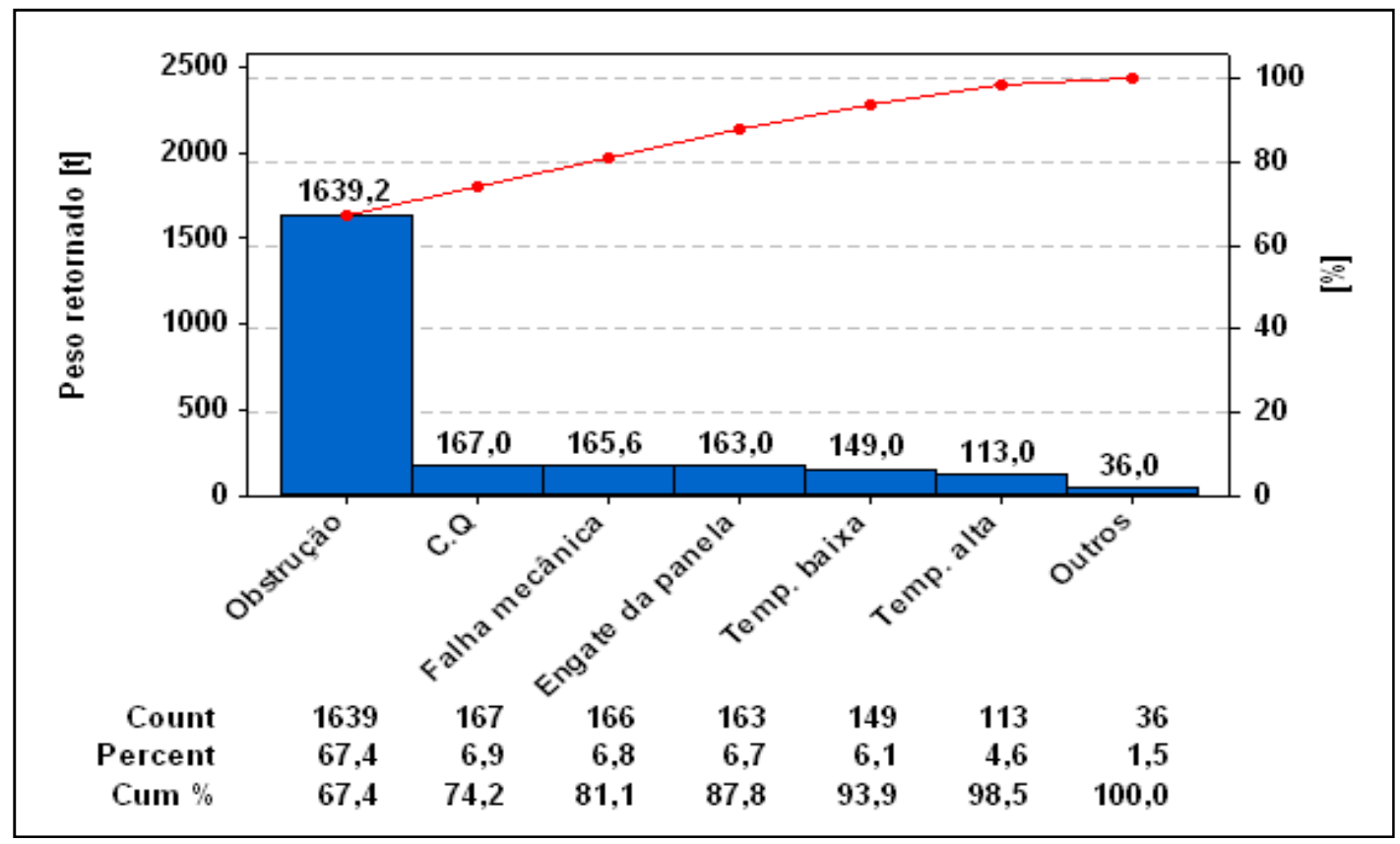

Figura 4 - Motivos de retorno de aço em aços ultrabaixo carbono com alto teor alumínio. [Fonte: Interna Usiminas].

Portanto, uma das ações para reduzir o índice de obstrução de válvula gaveta é a redução da quantidade alumina presente no aço. Neste trabalho serão apresentadas as ações tomadas para reduzir a quantidade de alumina no aço substituindo-se parcialmente o alumínio pelo ferro silício como agente desoxidante e exotérmico eliminando os problemas de lingotabilidade.

\section{MATERIAIS E MÉTODOS}

Visando conhecer os constituintes presentes no material aderido à válvula do aço ultrabaixo carbono com alto teor de silício e alumínio, separou-se uma válvula que havia sido obstruída e retirou-se uma amostra do material para realizar um estudo detalhado. Essas amostras foram cortadas, embutidas e polidas. Posteriormente, foram enviadas ao microscópio óptico e eletrônico de varredura (MEV) e realizado análise por espectrometria de energia dispersiva (EDS) para identificação dos constituintes presentes. 
Após essa análise elaborou-se um plano de experiência para acompanhar a produção no desgaseificador $\mathrm{RH}$ e no lingotamento contínuo. Inicialmente fez-se um balanço de massa para determinar qual o peso teórico de ferro silício necessário para substituir parte do alumínio utilizado tanto na desoxidação do aço quanto no aquecimento com sopro de oxigênio.

No período dessa experiência foram produzidas e acompanhadas 25 corridas. Amostras de aço foram retiradas durante o tratamento das corridas e enviadas ao laboratório onde foram preparadas e analisadas no espectrômetro de massa. Com base nos dados obtidos determinou-se o rendimento desse ferro silício, ajustando os valores a serem adicionados.

\section{RESULTADOS E DISCUSSÃO}

Visando compreender melhor o fenômeno de obstrução de válvula gaveta e buscando subsídios para explicar as possíveis causas dessas obstruções, foi separada uma válvula gaveta obstruída apresentada na figura 5.

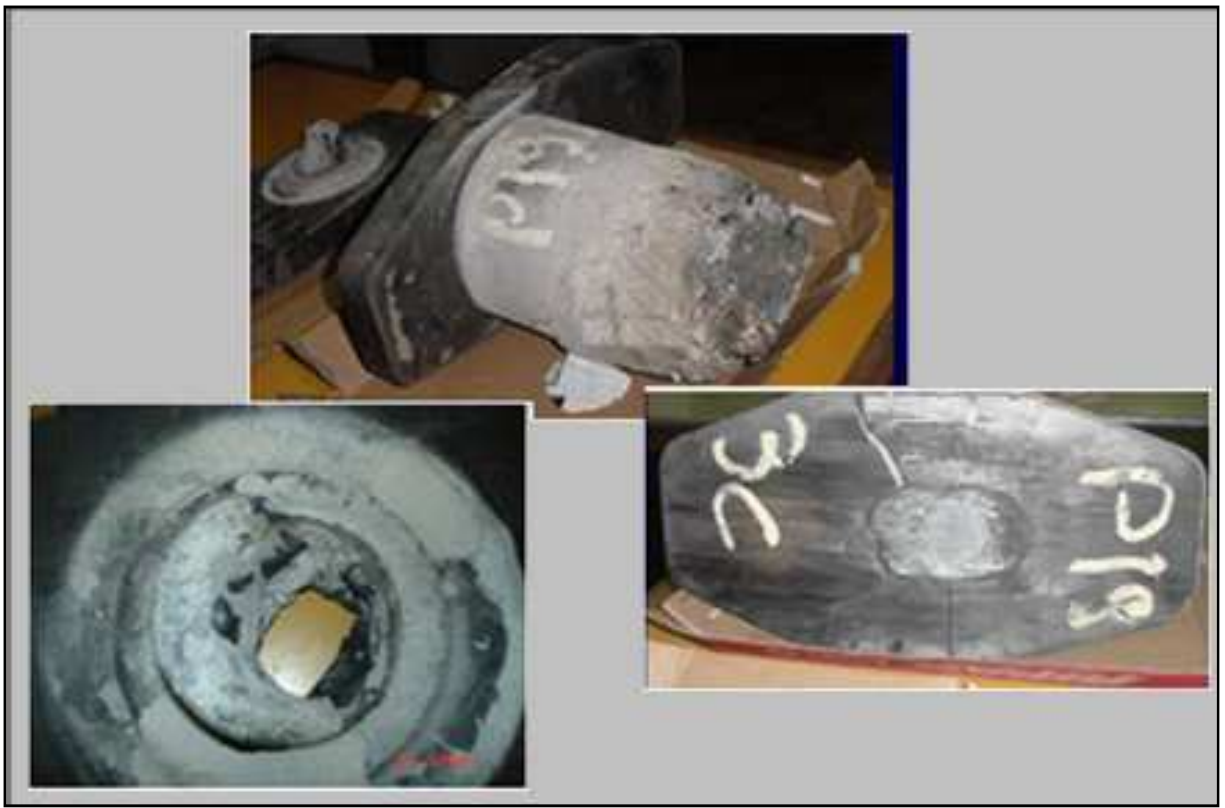

Figura 5 - Válvula gaveta obstruída. [Fonte: Interna Usiminas].

Para facilitar a visualização do material depositado, parte do refratário da válvula gaveta foi quebrado, deixando exposta a superfície metálica e óxidos aderidos, sendo realizado um corte transversal na mesma de onde retirou-se amostras do material. Observa-se na figura 6 regiões ricas em material não metálico (região escuras 1 e 2) e regiões ricas em aço (regiões claras 3 e 4). Nota-se também o local da obstrução da válvula gaveta onde a passagem de aço foi completamente obstruída pelo material não metálico que acumulou-se no sentido da extremidade para o centro interrompendo o fluxo de aço. A parte cilíndrica inferior refere-se ao material solidificado dentro da válvula superior. 


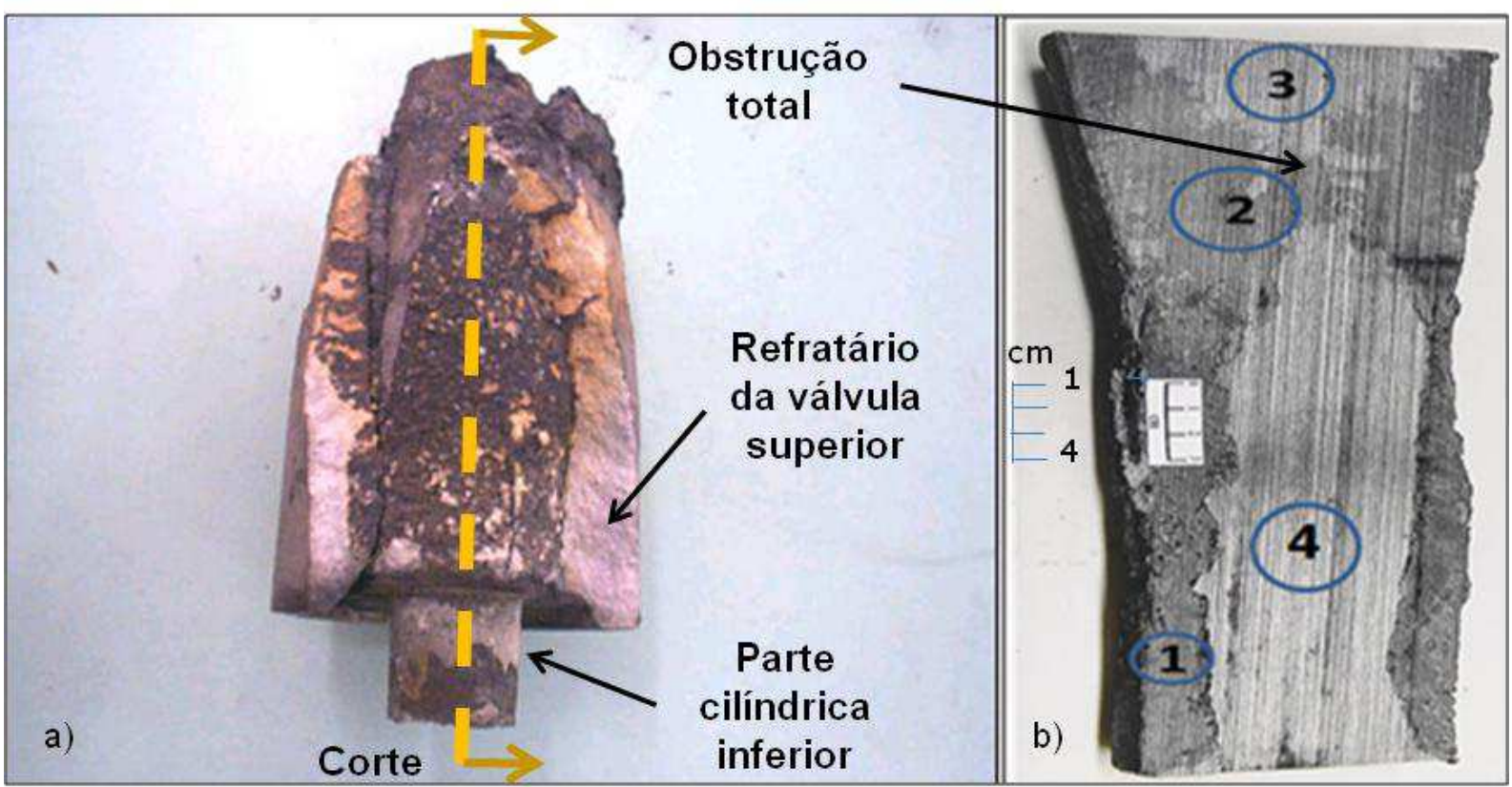

Figura 6 - a) Material solidificado na válvula superior obstruída e b) corte longitudinal na válvula superior. [Fonte: Interna Usiminas].

Para realizar a análise dos elementos presentes, preparou-se duas amostras das regiões 1 e 2, cortando-se uma fatia, embutindo em resina e polindo a superfície. Realizou-se uma análise por EDS e verificou-se que as inclusões são formadas principalmente de alumínio seguida de oxigênio e cálcio. Isto sugere a possibilidade da presença de alumina e aluminato de cálcio. O resultado dessa análise é apresentado na figura 7 .

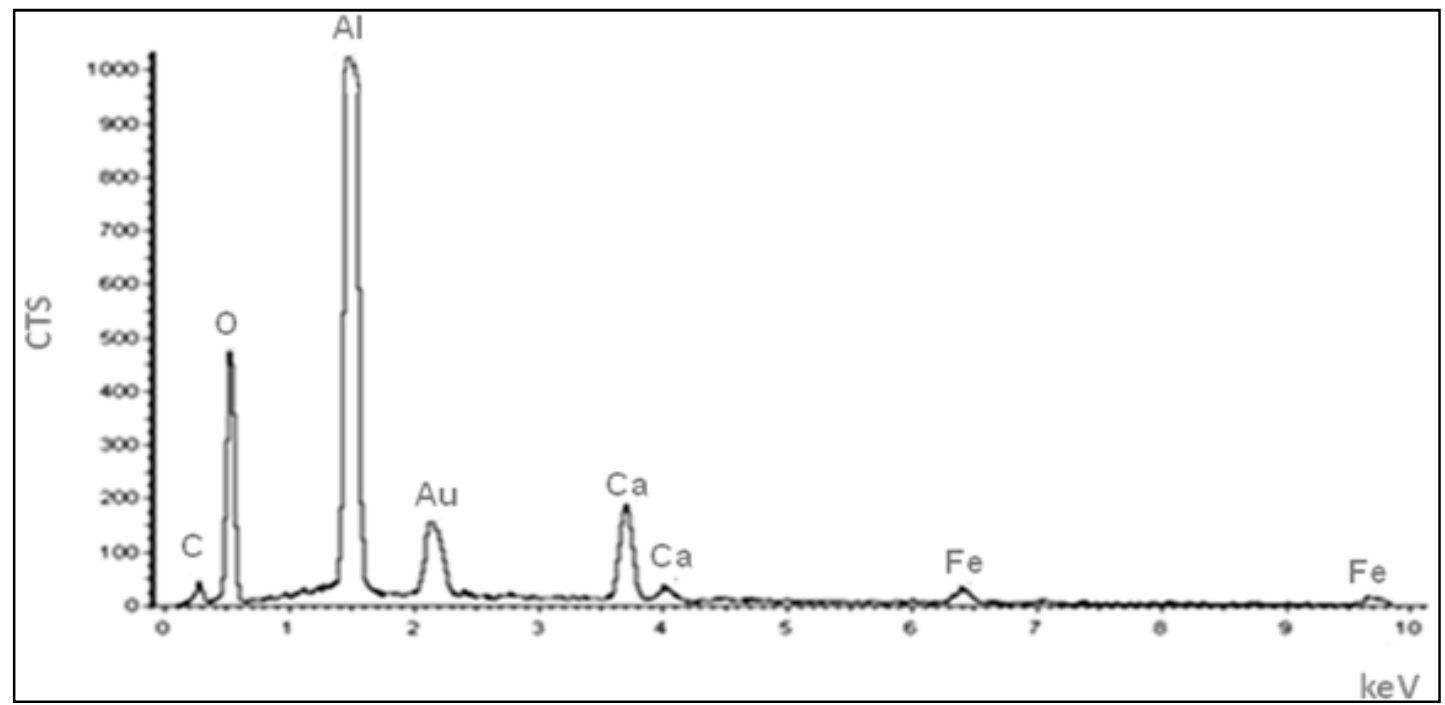

Figura 7 - Resultado da análise de EDS nas inclusões encontradas na região 1 e 2 do material retirado da válvula superior obstruída. [Fonte: Interna Usiminas].

Com objetivo de identificar a intensidade dessas inclusões, foi realizada análise elementar via EDS do material solidificado da válvula gaveta. Observa-se um misto de inclusões e aço. Nota-se nas micrografias 8(a) e 8(b) alta densidade de inclusões. Com uma maior ampliação, observa-se com mais nitidez nas micrografias 8(c) e 8(d) aglomerados de inclusões depositadas no interior da válvula gaveta formando clogging. 

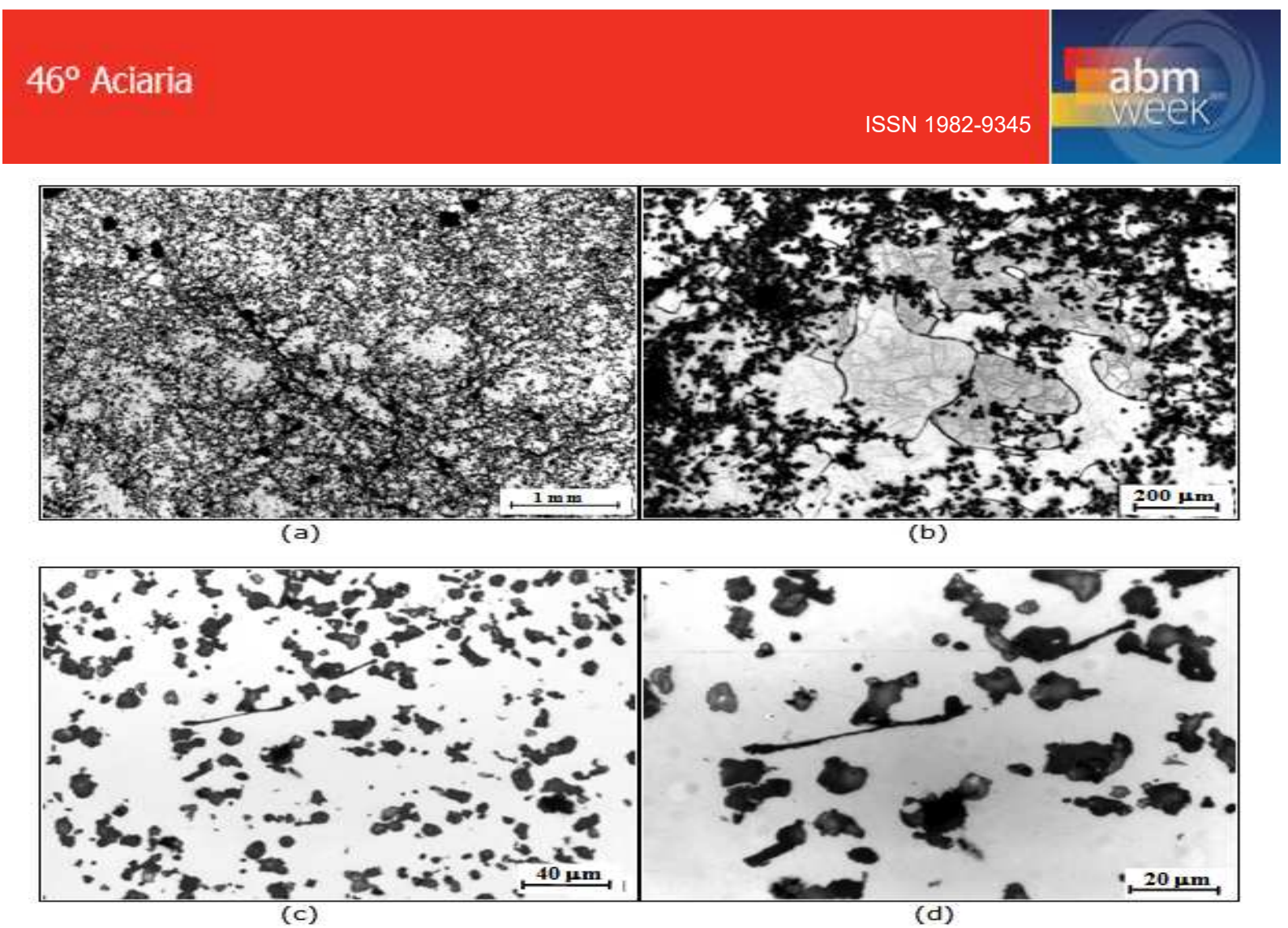

Figura 8 - Micrografia das amostras apresentando inclusões encontradas na região 1 e 2 do material retirado na válvula obstruída. [Fonte: Interna Usiminas].

Nota-se que a causa raiz das obstruções de válvulas são inclusões de alumina formada principalmente na desoxidação e aquecimento do aço durante o tratamento. Portanto, o modo mais eficaz de se solucionar o problema das obstruções é reduzir a geração de inclusões de alumina no aço.

Para reduzir a quantidade de alumina substituiu-se o alumínio pelo ferro silício como agente desoxidante. Calculou-se a quantidade de ferro silício a ser adicionada através de um balanço de massa e do rendimento obtido nas corridas experimentais. Elaborou-se uma tabela que varia a quantidade a ser adicionada em função do oxigênio dissolvido no aço, conforme tabela 1.

Tabela 1 - Tabela para adição de ferro silício em função do teor de oxigênio dissolvido.

\begin{tabular}{l|l}
\hline Oxigênio dissolvido $(\mathrm{ppm})$ & Peso de ferro silício $(\mathrm{kg})$ \\
\hline$<600$ & 2200 \\
\hline 601 a 900 & 2300 \\
\hline$>900$ & 2400 \\
\hline
\end{tabular}

Fonte: Interna Usiminas.

Outra fonte de geração de alumina no aço é a utilização de alumínio para aquecimento. Para redução dessa alumina optou-se também por substituir o alumínio de sopro pelo ferro silício como agente exotérmico. As entalpias de formação de alumina e sílica são apresentadas nas equações 1 e 2.

$\Delta \mathrm{Hf}^{\circ} \mathrm{Al}_{2} \mathrm{O}_{3}=-400 \mathrm{kcal} / \mathrm{mol}(1)$

$\Delta \mathrm{Hf}^{\circ} \mathrm{SiO}_{2}=-216 \mathrm{kcal} / \mathrm{mol}(2)$

Após essas análises desenvolveu-se um plano de experiência com acompanhamento de 25 corridas. O teste iniciou-se no $3^{\circ}$ trimestre de 2014 , e até o final de janeiro de 2015 foram produzidas 74 corridas. Com a utilização dessa prática 
a maior parte da alumina gerada foi substituída por sílica que flutua mais rapidamente causando menos obstruções.

Devido às diferenças de entalpias das reações, houve necessidade de incremento referente ao peso de silício e do volume de oxigênio soprado. A quantidade de material obtida experimentalmente utilizando o ferro silício foi $8,4 \mathrm{~kg} /{ }^{\circ} \mathrm{C}$ e utilizando 0 alumínio foi de $5,3 \mathrm{~kg} /{ }^{\circ} \mathrm{C}$. A substituição de alumínio tanto para desoxidação quanto para aquecimento gerou uma redução de aproximadamente $170 \mathrm{~kg}$ de alumínio por corrida. Essa substituição implica na redução de aproximadamente $320 \mathrm{~kg}$ de alumina gerada no aço, tornando-o menos propício a formação de clogging na válvula gaveta. A figura 9 mostra a comparação do consumo específico de alumínio e ferro silício para as situações de rotina e as testadas.

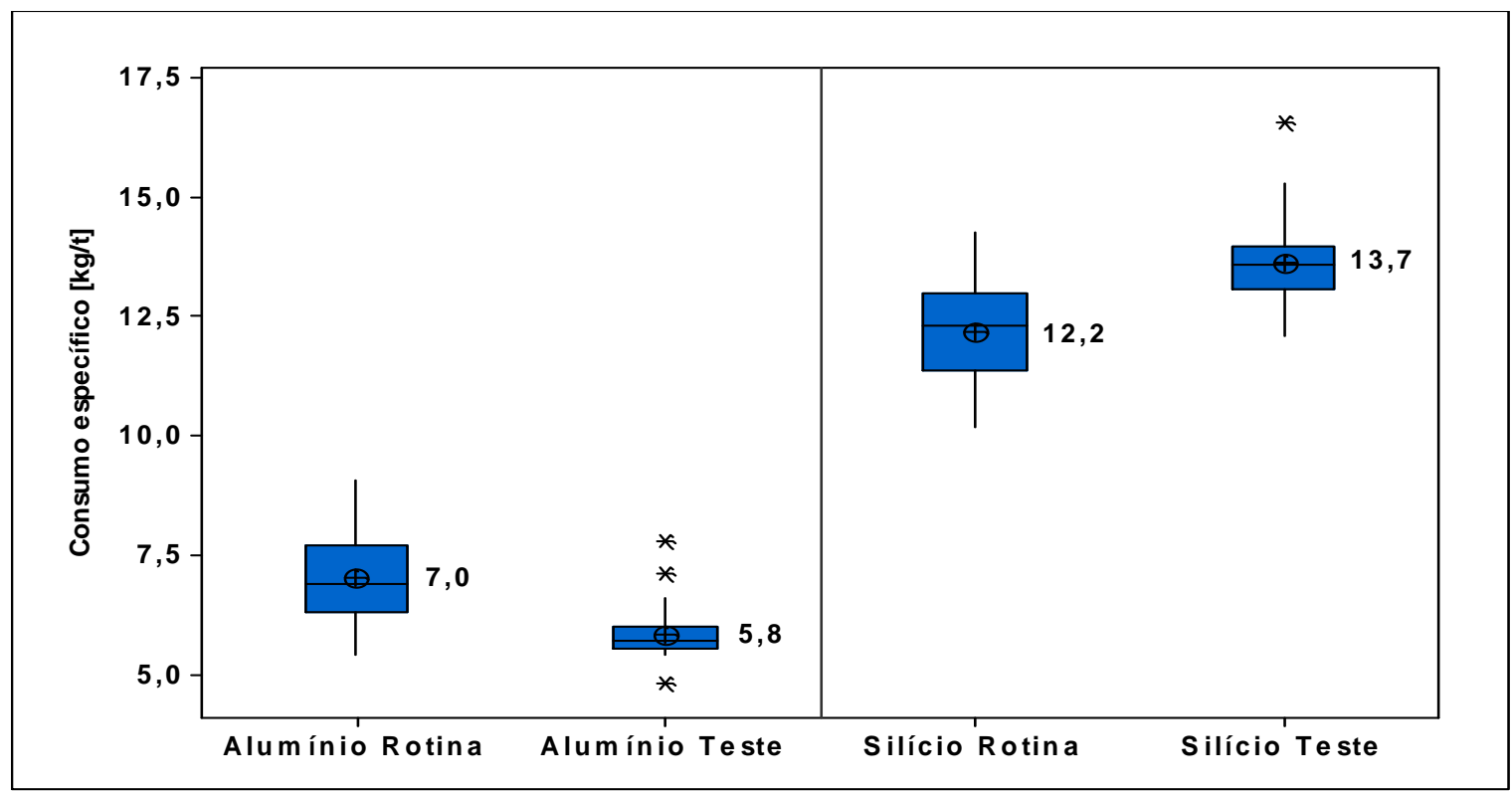

Figura 9 - Consumo específico de alumínio e ferro silício no aço. [Fonte: Interna Usiminas].

Os dados apresentados na figura 10 mostram a eficácia da prática adotada. A redução de alumina tornou-se uma prática essencial para eliminação da formação de clogging na válvula gaveta.

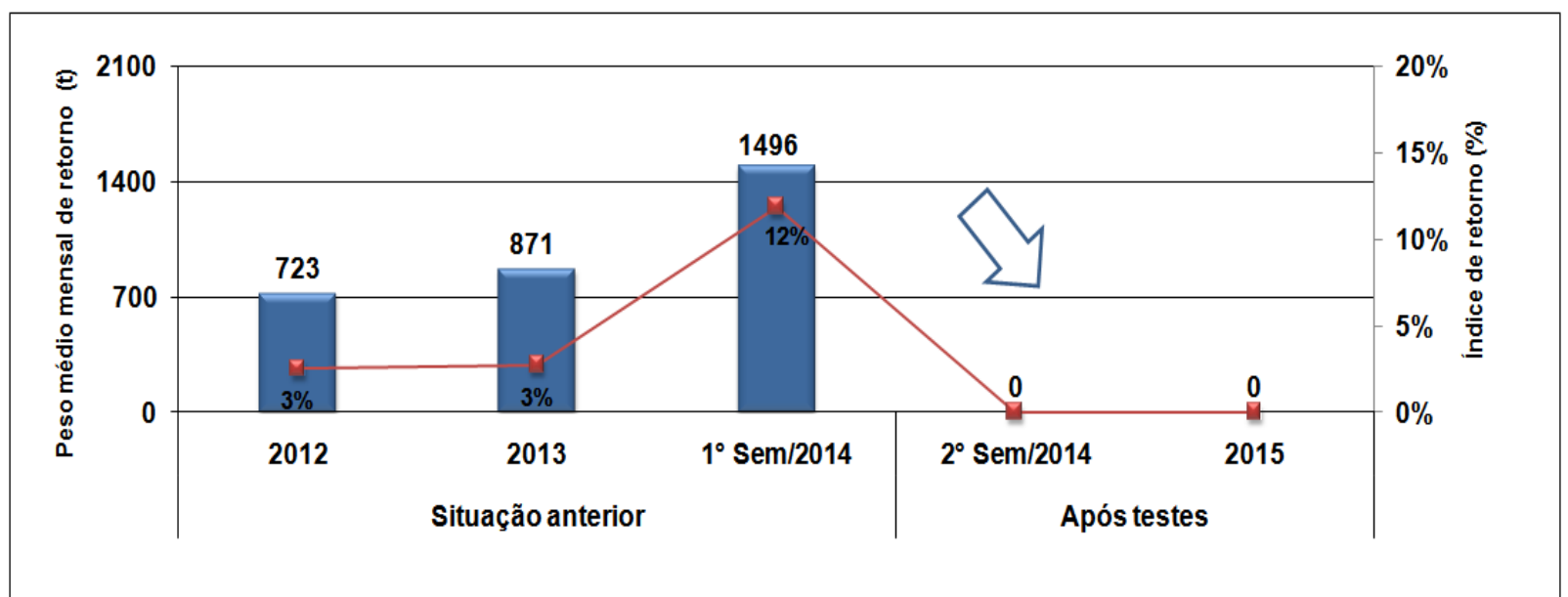

Figura 10 - Resultados de retono de aço ocasionado por obstrução de válvula gaveta. [Fonte: Interna Usiminas]. 
Com alteração do processo, observa-se a eliminação da formação de clogging, e consequentemente, eliminação das interrupções de série por obstrução de válvula gaveta, conforme visto na figura 11 .

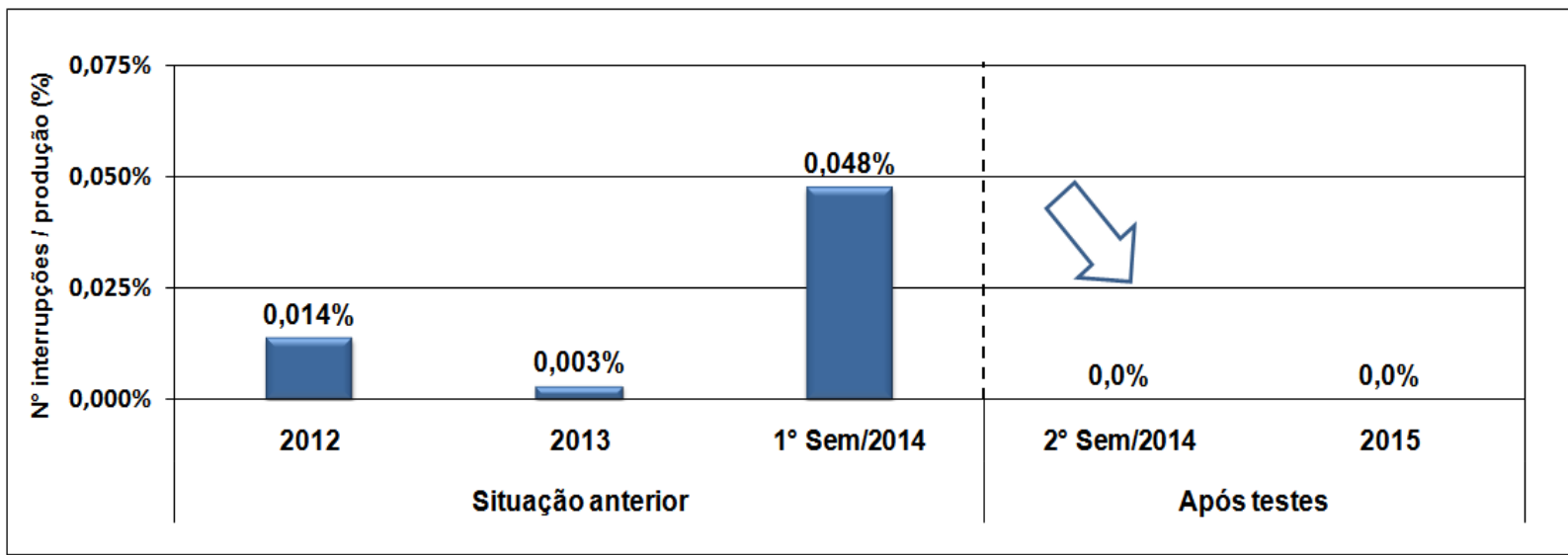

Figura 11 - Índice de frequência de interrupções de séries em função da produção. [Fonte: Interna Usiminas].

\section{CONCLUSÃo}

A substituição do alumínio pelo ferro silício como agente desoxidante e exotérmico resultou na eliminação do clogging na válvula gaveta da panela. Com essa prática obteve-se uma redução de aproximadamente $170 \mathrm{~kg}$ de alumínio por corrida o que corresponde a uma redução de aproximadamente $320 \mathrm{~kg}$ de alumina gerada no aço, eliminando a formação de clogging na válvula gaveta e consequentemente as interrupções de série por esse motivo.

Com a produção de 84 corridas após a data de implantação da nova prática não foi registrado nenhum retorno de aço provocado pela obstrução de válvula gaveta, assim como não ocorreu nenhuma interrupção de série por esse motivo.

\section{Agradecimentos}

Os autores agradecem ao especialista Okitomo Kunitake e ao técnico Hélio Alexandre Alves pelo apoio técnico durante a elaboração deste trabalho.

\section{REFERÊNCIAS}

1 RASTOGI, R.; CRAMB, A.W. Inclusion Formation and Agglomeration in Aluminum Killed Steels. In: STEELMAKING CONFERENCE, Baltimore Proceedings Warrendale: Iron \& Steel Society, pp.789 - 829, 2001.

2 SAKAGAMI, R.; SASAI, T. Formation Mechanism of Silica Inclusion During Solidification of Fe-Si-O Alloys. Journal of the Iron and Steel Institute of Japan, pp. $1288-1295$, 1983.

3 MILLS, E. C.; BILLANY, T.J.H.; NORMANTON, F.S.; WALKER, B.; GRIEVERSON, P. "Causes of Stricker Breakout During Continuous Casting" - IRONMKING AND STEELMAKING, vol 18, n.2, pp. $253-265,1991$.

4 ZHANG. L.; TOMAS. B. G. Alumina Inclusion Behavior During Steel Desoxidation. In: STEELMAKING CONFERENCE, Venice. pp. $2.77-2.86,2002$

5 FACO, R. J. Levantamento das inclusões nos principais grupos de aços produzidos em aciaria do tipo LD. Dissertação de Mestrado, USP, pp. 12 - 25, 2005. 